\title{
Protein Bodies in Cotyledon Cells Exhibit Differential Patterns of Legumin-Like Proteins Mobilization during Seedling Germinating States
}

\author{
Jose C. Jimenez-Lopez ${ }^{1,2^{*}}$, Maria C. Hernandez-Soriano ${ }^{3}$ \\ ${ }^{1}$ The UWA Institute of Agriculture, The University of Western Australia, Perth, Australia; ${ }^{2}$ Department of Biochemistry, Cell and \\ Molecular Biology of Plants, Estacion Experimental del Zaidin (EEZ), National Council for Scientific Research (CSIC), Granada, \\ Spain; ${ }^{3}$ School of Agriculture and Food Sciences, Faculty of Science, The University of Queensland, Saint Lucia, Australia. \\ Email: ${ }^{*}$ jose.jimenez-lopez@uwa.edu.au, ${ }^{*}$ jcjimenez175@gmail.com, ${ }^{*}$ josecarlos.jimenez@eez.csic.es
}

Received November $14^{\text {th }}, 2013$; revised December $15^{\text {th }}, 2013$; accepted December $26^{\text {th }}, 2013$

Copyright (C) 2013 Jose C. Jimenez-Lopez, Maria C. Hernandez-Soriano. This is an open access article distributed under the Creative Commons Attribution License, which permits unrestricted use, distribution, and reproduction in any medium, provided the original work is properly cited.

\begin{abstract}
Olive (Olea europaea L.) tree is one of the most extensive and important agricultural crop in Mediterranean countries due to its beneficial health and nutritional properties and its high economic value. Currently, olive tree constitutes the sixth most important cultivated plant in the world, spreading from the Mediterranean region of origin to new production areas such as Australia, South and North America and South Africa. However, the mobilization processes of storage materials i.e. reserve proteins during seed germination, which are largely involved in essential physiological process including plant growth and development, remain poorly understood. Morphometric and immunohistochemistry analyses of protein bodies contained in olive seed storage tissues, cotyledon and endosperm, were performed by using different microscopy techniques, including light (bright-field and fluorescence) microscopy and transmission electron microscopy. Furthermore, we used legumin-like proteins (11S-type globulins) as a molecular marker to study the mobilization of reserve proteins from PBs of cotyledons at germinating seedling stages by using immunofluorescence assays. Results demonstrated that cotyledon and endosperm are characterized by distinct PBs populations containing legumin-like proteins, distinctly discriminated by the number of PBs per cell and tissue, size, immunofluorescence and histochemical staining. These features reflect differential PBs biogenesis during development and maturation processes in olive seed tissues endosperm and cotyledon, in relation to proteins (polypeptides) final composition, SSPs processing and/or packaging during seed maturation. Three different mobilization patterns of legumin-like proteins were identified for the first time in cotyledon PBs during seedling germinating process. Mature proteins composition and/or processing, cell types and enzyme composition and/or differential activation have been discussed as key features determining how proteins mobilize from PBs for further degradation in the cotyledon.
\end{abstract}

Keywords: $11 \mathrm{~S}$ Globulins; Cotyledon; Endosperm; In Vitro Germination; Legumin-Like Proteins; Olea europaea L.; Protein Bodies; Seed Proteins Mobilization

\section{Introduction}

The effective mobilization of seed storage reserves and their degradation during seed germination is a crucial physiological process in the plants life cycle [1].

Seed Storage proteins (SSPs) in dicotyledonous plants, mainly legumin-like (11S globulins) and vicilin-like (7S globulins) proteins, accumulate in specialized storage cells of the embryonary axis (cotyledon and endosperm)

${ }^{*}$ Corresponding author.
[2], and are protected against uncontrolled premature degradation through two major mechanisms, 1) structural features that prevent cleavage by proteases simultaneously present in the same compartment $[3,4]$ and 2) protein mature forms being transported and deposited into large membrane-bounded specialized compartments like PBs and protein storage vacuoles (PSVs) protecting them from cytoplasmic proteases [2]. PSVs are unique to plants, and no equivalent organelle is present in animals or yeast [5]. Furthermore, PSVs are not restricted to de- 
veloping seed tissue, but also occur in tips cells at the primary roots in young germinating seedlings [6].

SSPs mobilization and degradation are key events during seed germination [7]. These are complex and multi-stages processes of developing plants, for which efficiency of reserve mobilization, and hence of seedling establishment itself, depends on the extent of reserve accumulation during seed development and maturation [8]. SSP degradation takes place after a (long) period of rest when seeds germinate and seedlings start growing, and where all these proteins are mobilized to nourish the seedling for plant development [2,9]. Moreover, the major metabolic events occurring during seed germination are different depending of the specie, as well as their genetically determined diversity seed morphology, physiological maturity, developmental pattern and chemical reserves $[2,10,11]$.

Mobilization of stored compounds during germination does not occur in all cells and seed tissues synchronically, following specific spatial and temporal patterns $[12,13]$. Sites of mobilization of the protein reserves coincide with the sites of growth and differentiation in the embryonic axes, such as in the cotyledons, where globulin's breaking down starts in the tissues near to pre-vascular strands and then proceeds toward the embryonic shoot. This sequence of events is time-schedule designed allowing the development of the vascular system and to continue with the proteins mobilization in the cotyledons and transport to the embryo axis cells [12].

In the present work, we have studied the morphometric and immunohistochemical characteristics of the PBs populations in mature seed reserve tissues, endosperm and cotyledon, and the differential cytological changes that occur in olive cotyledon during seed germination, with a focus in PBs proteins mobilization toward a better understanding of the physiological process accompanying stored (legumin-like) proteins degradation along seed in vitro germination stages.

\section{Material and Methods}

\subsection{Plant Material}

Mature seeds were obtained from the olive (Olea europaea L.) trees cv. Picual grown in the "Estación Experimental del Zaidín", Granada (Spain).

\subsection{In Vitro Germination of Olive Embryos}

Mature seeds without endocarp were surface-sterilized for $1 \mathrm{~min}$ with $70 \%(\mathrm{v} / \mathrm{v})$ ethanol followed by stirring in $15 \%$ ( $/ \mathrm{v}$ ) solution of commercial bleach plus some drops of Tween-20 during $10 \mathrm{~min}$. After rinsing five times with sterile distilled water, the embryos were sepa- rated from the endosperm and placed in sterilized glass tubes containing solid medium Murashige and Skoog (MS) [14] plus $0.025 \%$ activated carbon to prevent the interfering secondary metabolites released from embryos. Cultures were kept in a growing chamber with cool white fluorescent tubes $\left(18 \mathrm{~W} \cdot \mathrm{m}^{-2}\right.$ Sylvania, Luxline Plus, Germany), $16 \mathrm{~h} \mathrm{light/day,} \mathrm{and} 24 \pm 1{ }^{\circ} \mathrm{C}$ of temperature. Cotyledons were collected from mature and imbibed (24 h) seeds at different point-times of in vitro germination and seedling growth.

\subsection{Microscopy Sample Preparation}

Cotyledon and endosperm were dissected out from mature olive seeds and individually processed for light and transmission electron microscopy. Samples were fixed for $24 \mathrm{~h}$ at $4{ }^{\circ} \mathrm{C}$ with a mix of $4 \%(\mathrm{w} / \mathrm{v})$ paraformaldehyde and $0.2 \%(\mathrm{v} / \mathrm{v})$ glutaraldehyde in $0.1 \mathrm{M}$ cacodylate buffer (pH 7.2). Samples were then dehydrated throughout an ethanol series and embedded in Unicryl resin (BBInternational, UK). After ultraviolet light polymerization of samples at $-20^{\circ} \mathrm{C}$ for $48 \mathrm{~h}$, both semi-thin $(1 \mu \mathrm{m})$ and ultra-thin sections $(70 \mathrm{~nm})$ were obtained using a Reichert-Jung Ultracut E microtome (Leica Microsystems, Germany). Semi-thin sections were placed on BioBondTM (BBInternational) coated slides. Ultra-thin sections were mounted on formwar coated 200 mesh nickel grids.

\subsection{Histochemistry}

For general histological observations, sections were stained with a mixture of $0.05 \%(\mathrm{w} / \mathrm{v})$ methylene blue and $0.05 \%(\mathrm{w} / \mathrm{v})$ Toluidine blue [15]. For protein localization, sections were stained with Ponceau S according to Parker (1965) [16]. Observations were carried out with Axioplan microscope (Carl Zeiss, Germany) and images were recorded with a ProGres C3 digital camera using the ProGres CapturePro v2.6 software (Jenoptik AG, Germany).

\subsection{Microscopy Immunolocalization of Legumin-Like (11S-Type Globulin) Proteins}

Immunofluorescent cytochemistry was carry out in semithin sections $(1 \mu \mathrm{m})$ through a sequential treatment with an incubation in blocking solution containing $1 \%(\mathrm{w} / \mathrm{v})$ bovine serum albumin (BSA) in phosphate buffered saline (PBS) solution ( $\mathrm{pH} 7.2$ ), following by an incubation overnight at $4{ }^{\circ} \mathrm{C}$ with an anti-11S antibody (diluted 1:500) ( $p 1$ antiserum raised in rabbits) [17], following by goatanti-rabbit IgG: Alexa Fluor 488-conjugated secondary antibody (Molecular Probes, USA) (diluted 1:2000 in blocking solution) for $1 \mathrm{~h}$ at $37^{\circ} \mathrm{C}$. In control sections the primary $\mathrm{Ab}$ was omitted. Samples fluorescence was preserved with an anti-fading agent (Citifluor/glycerol/PBS, 
Sigma). The sections were observed and analyzed in an epifluorescence Zeiss Axioplan (Carl Zeiss, Germany) using the filter combination: BP365, FT395 and LP397. Images were obtained with a ProGres C3 digital camera using the ProGres CapturePro 2.6 software (Jenoptik AG, Germany).

For immunogold experiments, ultra-thin sections were treated with a blocking solution (5\% (w/v) (BSA), $0.1 \%$ $(\mathrm{v} / \mathrm{v})$ Tween-20 in PBS), a diluted (1:500) solution of the p1 antiserum in blocking solution, a 1:1000 solution of the secondary antibody (goat anti-rabbit IgG: $15 \mathrm{~nm}$ gold) (BBInternational), and finally contrasted using a $5 \%(\mathrm{w} / \mathrm{v})$ uranyl acetate solution for $30 \mathrm{~min}$ at room temperature. Observations and analyses of samples were carried out with a JEM-1011 transmission electron microscope (JEOL, Japan). Control reactions were carried-out by omitting the primary $\mathrm{Ab}$.

\subsection{Quantitative Parameters and Statistical Analyses}

Quantitative morphometric analyses of endosperm and cotyledon PBs features ( $\mathrm{N}^{\circ}$ of PBs/cell, PBs area), Ponceau $\mathrm{S}$ stainability, and immunofluorescence intensity analyses were performed on serial semithin and ultrathin sections of endosperm and cotyledons from 300 cells from 30 sections randomly chosen from 15 mature seeds. Parameters measurements were performed with the ImageJ v1.47 software (NIH, USA).

Differences among endosperm and cotyledon for PBs area, PBs/cell, Ponceau S stainability and immunofluorescence intensity were examined with Mann-Whitney U tests $(\mathrm{p}<0.01)$ using SigmaPlot 12.3 (Systat Software Inc., 2011). Two-tails Pearson's correlation coefficients were estimated by using SPSS 21 (2012) to determine relationships among these parameters.

\section{Results}

\subsection{Analysis of Mature Olive Seed Protein Bodies}

Mature olive seeds consist of a brown seed coat (Figure 1(A)) and a relatively thick layer of white endosperm, which surrounds a white embryo (Figures 1(B) and (C)). In the mature stage, endosperm and embryo can be clearly identified (Figure 1(D)), with the embryo exhibiting two cotyledons and a radicle.

Mature olive embryos were in vitro germinated, and the cotyledon material was processed for microscopy analysis of legumin-like (11S-type globulins) proteins. These proteins were used as biomarker for the study of SSPs mobilization during seeds imbibition and at different seedling germinating stages (Figure 1(E)).

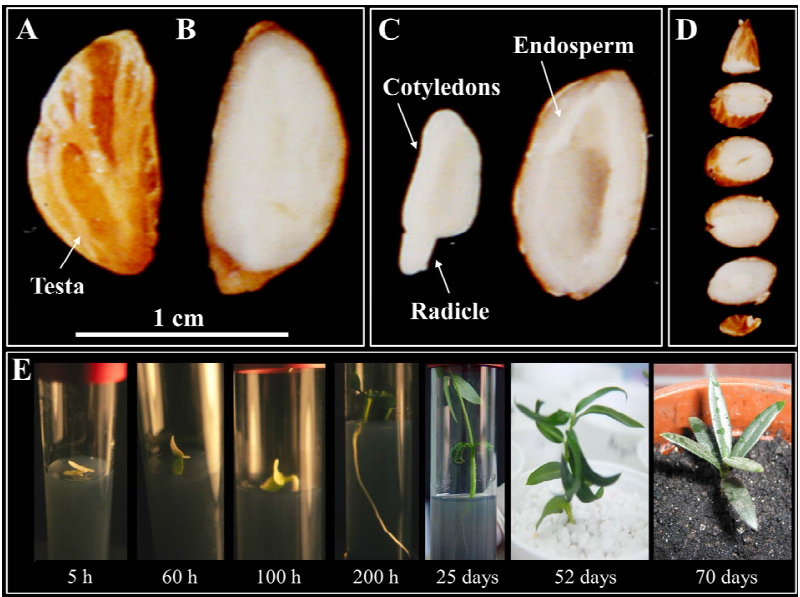

Figure 1. Mature olive seed: macroscopic images and in vitro germination. (A) Mature olive seed covered by a thin brown coat; (B) horizontal and $(C)$ cross section of the seed showing the thin brown coat that is attached to the thick white endosperm with embryo; (D) the macroscopic images of the dissected embryo from mature seed is showing the radicle and cotyledons, and a horizontal cross section of the seed without embryo, is showing the endosperm white tissue. (E) Consecutive steps of mature embryo in vitro germination and seedling growth, until the plant was transferred to a pot with soil.

Morphological differences of the cells, as well as a differential distribution of the storage materials integrating both tissues, endosperm and cotyledon, were observed at the mature stage of olive seed (Figure 2). PBs of endosperm and cotyledon cells are discretely occupying part of the cytoplasm space, while lipid bodies (LBs) of $<1 \mu \mathrm{m}$ of diameter are surrounding PBs, with broader distribution in endosperm tissue and completely occupying the cytoplasm spaces in between PBs (Figure 2, picture 1 and 2). Moreover, LBs distribution in cotyledon differed from endosperm tissue, since LBs $(>1 \mu \mathrm{m}$ of diameter) are almost exclusively surrounding the PBs (Figure 2, picture 3 and 4), providing visible cytoplasmic spaces.

Endosperm and cotyledon were processed for TEM and legumin-like (11S-type globulins) proteins detection in PBs. Immunogold assay showed gold grains almost exclusively located inside the PBs (gold grains highlighted with arrows) compared to the negative control (Figure 2, picture 2 and 4, respectively) in both, endosperm (Figure 2, picture 1) and cotyledon (Figure 2, picture 3).

Few grains were observed on the LBs near PBs. Ultrastructural analysis of endosperm (Figure 2, picture 2) showed the presence of the dense PBs (between 1 and 10 $\mu \mathrm{m}$ of diameter).

PBs content consisted in electron-dense aggregated material, while cotyledon cells (Figure 2, picture 4) 

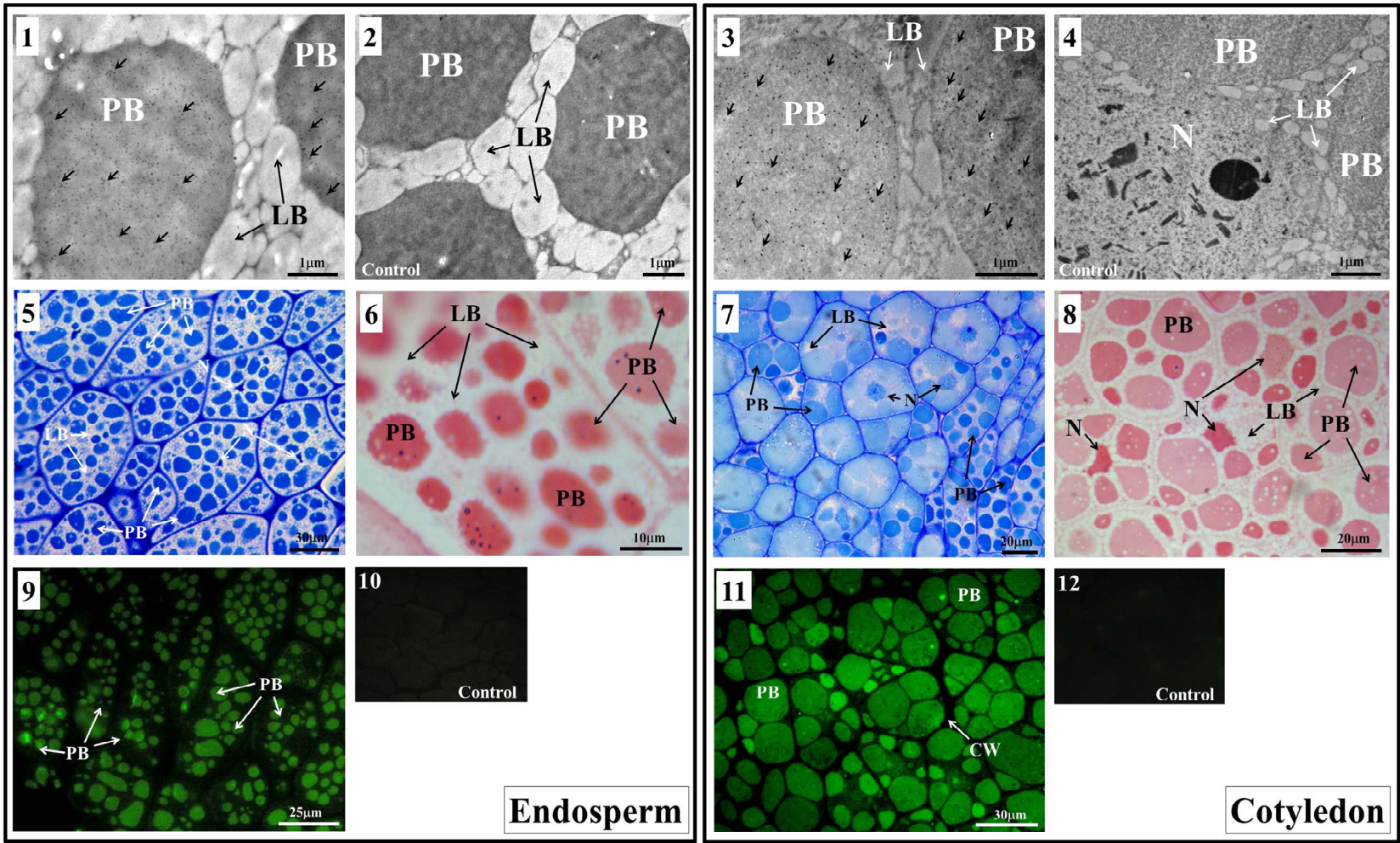

Figure 2. Stainability and immunohistochemical analyses of the mature olive endosperm and cotyledon tissues. Ultrastructural analysis of mature endosperm (1 and 2) and cotyledon (3 and 4) (190DAA), showing PBs surrounded by LBs and filling up the cytoplasmic space. Immunogold analysis of both tissues (1 and 3) showed gold grains located almost exclusively in the PBs compared to the controls ( 2 and 4, respectively). Gold grains were highlighted with arrows. Mature endosperm (5) and cotyledon (7) semithin sections stained with Toluidine-blue. Similar type of semithin sections (6 and 8 , respectively) stained with Ponceau S. Immunofluorescence assays showed legumin-like proteins located in endosperm (9) and cotyledon (11) PBs. Auto-fluorescence controls did not show significant signal (10 and 12, respectively) coming from PBs of both seed tissues. LB = lipid body; $\mathbf{N}=$ nucleus; $\mathbf{P B}=$ protein body.

showed the presence of lightly dense PBs (between 2 and $25 \mu \mathrm{m}$ of diameter).

The analysis of the endosperm showed regular size and distribution of PBs, with an average number per cell of $16.50 \pm 5.00$ (median 16.00) PBs per cell, an average PB area of $10.80 \pm 8.10 \mu \mathrm{m}^{2}$ (median 8.20) (Table 1), and homogeneous Toluidine blue color (Figure 2, picture 5), and Ponceau S (Figure 2, picture 6) stainability (Table 1). Otherwise, the analysis of cotyledon tissue showed an irregular distribution of PBs and higher variability in PBs number and area that in endosperm, with an average number per cell of $5.20 \pm 2.00$ (median 5.00), an average area of $22.70 \pm 20.00 \mu \mathrm{m}^{2}$ (median 16.00).

Differences with endosperm were also determined for PBs sizes in individual cells (Table 1) as well as differential Toluidine-blue (Figure 2, picture 7) and Ponceau S (Figure 2, picture 8) stainability among PBs population and cells (Table 1). In addition, histochemical features in both tissues were also detected using immunohistochemistry assays, with endosperm (Figure 2, picture 9) exhibiting a more homogeneous immunofluorescence intensity of PBs inside individual cells in comparison to cotyledon cells (Table 1 and Figure 2, picture 11). Control images (Figure 2, pictures 10 and 12) did not show significant auto-fluorescence signal for any of the seed tissues analyzed.

Significant statistical differences $(p<0.001$, MannWhitney $U$ test) were estimated among endosperm and cotyledon for PBs area, PBs/cell, Ponceau S stainability and immunofluorescence intensity. Pearson's correlation coefficients indicated that no correlation exists among the analyzed variables except for a negative correlation between PBs area and immunofluorescence intensity in cotyledon (Pearson coefficient $=-0.218, p=0.008$ ).

\subsection{Legumin-Like Proteins Mobilization at Different Seedling Germinating Stages}

Marked differences of 11S-type globulin fluorescence intensity were found among PBs population in mature cotyledons (Figure 3, picture 1), while no significant cytoplasmic fluorescence was detected. 
Table 1. Morphometric, stainability and immunohistochemistry analyses of olive seed PBs. Average and standard deviation, maximum (max), minimum (min) and median values of parameters analyzed of PBs in endosperm and cotyledon cells.

\begin{tabular}{|c|c|c|c|c|}
\hline & \multicolumn{2}{|c|}{ Area $\left(\mu \mathrm{m}^{2}\right)$} & \multicolumn{2}{|c|}{ Total $\mathrm{N}^{\circ}$ of PBs/cell } \\
\hline & Endosperm & Cotyledon & Endosperm & Cotyledon \\
\hline Average & $10.80 \pm 8.10$ & $22.70 \pm 20.00$ & $16.50 \pm 5.00$ & $5.20 \pm 2.00$ \\
\hline Max & 37.70 & 97.05 & 33.00 & 12.00 \\
\hline Min & 0.44 & 0.96 & 5.00 & 2.00 \\
\hline \multirow[t]{3}{*}{ Median } & 8.20 & 16.00 & 16.00 & 5.00 \\
\hline & \multicolumn{2}{|c|}{ Ponceau S stainability (a.u.) } & \multicolumn{2}{|c|}{ Immunofluorescence intensity (a.u.) ${ }^{\mathrm{a}}$} \\
\hline & Endosperm & Cotyledon & Endosperm & Cotyledon \\
\hline Average & $146.00 \pm 9.00$ & $172.00 \pm 13.00$ & $124.80 \pm 7.90$ & $133.40 \pm 9.60$ \\
\hline Max & 161.00 & 197.00 & 144.50 & 150.10 \\
\hline Min & 122.00 & 138.00 & 107.30 & 124.30 \\
\hline Median & 149.00 & 172.00 & 134.20 & 124.10 \\
\hline
\end{tabular}

${ }^{\mathrm{a}}$ Immunofluorescence intensity values after subtracting auto-fluorescence. a.u. = arbitrary units.

At $15 \mathrm{~h}$ of imbibition (Figure 3, picture 2) intense labeling was diffusely visible, reflecting the initiation of the re-organization and beginning of proteins mobilization process in $\mathrm{PBs}$ when seed metabolism activation took place after a quiescence period.

Further steps of in vitro germination, from 10 to $100 \mathrm{~h}$ (Figure 3, pictures 2 to 6), showed PBs undergone reorganization and fusion, leading to a size increase, to finally form a single large vacuole full of proteins occupying the whole cytoplasm after 4 days of in vitro germination. Additionally, few bright fluorescent spots appeared in the marginal side of the cell cytoplasm (Figure 3, picture 6).

From the $5^{\text {th }}$ to $10^{\text {th }}$ day of in vitro germination (Figure 3, pictures 7 to 24), substantial changes in 11S-type protein mobilization occurred among cotyledon cells. Three different patterns of proteins mobilization were identified, and named as 1) "Holes" (pattern 1); 2) "Trees-like Structures" (pattern 2); and 3) "Whole Disintegration" (pattern 3).

In the pattern 1 (Figure 3, pictures 7 to 12), the initiation of regular shape small holes in the marginal cytoplasm can be observed, with an increase in size as more protein mobilize from the large vacuole to the cytoplasm Similar size was determined for all the cells at equivalent time-lapse as the protein degradation progress.

In the pattern 2 (Figure 3, pictures 13 to 18), an initial mark (Figure 3, picture 13, white arrows) is appreciated in the periphery of the cytoplasm as the initiation of the characteristic "Trees-like Structures" pattern. These structures were growing and usually completed at the opposite side of the cytoplasm side. Proteins mobiliza- tion continued from these structures inside of the large vacuole.

In the pattern 3 (Figure 3, pictures 19 to 24), storage proteins from the putative tiny packed state inside of the large vacuole are getting loose as the initiation of the protein mobilization begins. This model showed that proteins are likely to be synchronically mobilized from the whole large vacuole.

A differential feature between these mobilization patterns is that "Trees-like Structures" and "Whole Disintegration" displayed an asynchrony in the progression of protein mobilization and degradation in comparison with the "Holes" pattern when different neighbor cells were analyzed.

The concomitant occurrence of two of the patterns described above for legumin-like proteins mobilization have also been frequently observed in several cells of the cotyledon (Figure 4).

After 11 days of germination, the cytoplasm of these cells showed variable number of protein clusters of different sizes and irregularly shaped, regardless the mobilization pattern.

From $11^{\text {th }}$ to $19^{\text {th }}$ day of in vitro germination (Figure 3, pictures 25 to 30), the immunofluorescence labeling of 11S-type globulins have almost disappeared in the cytoplasm, likely due to completed storage proteins mobilization and degradation, which might have occurred in order to supply $\mathrm{C}, \mathrm{N}$ and $\mathrm{S}$ to the embryo for the plant development support. In addition, during the last 10 days of seedling growth numerous and clearly identifiable chloroplasts can be observed in the cell cytoplasm (mostly due to their auto-fluorescence). 

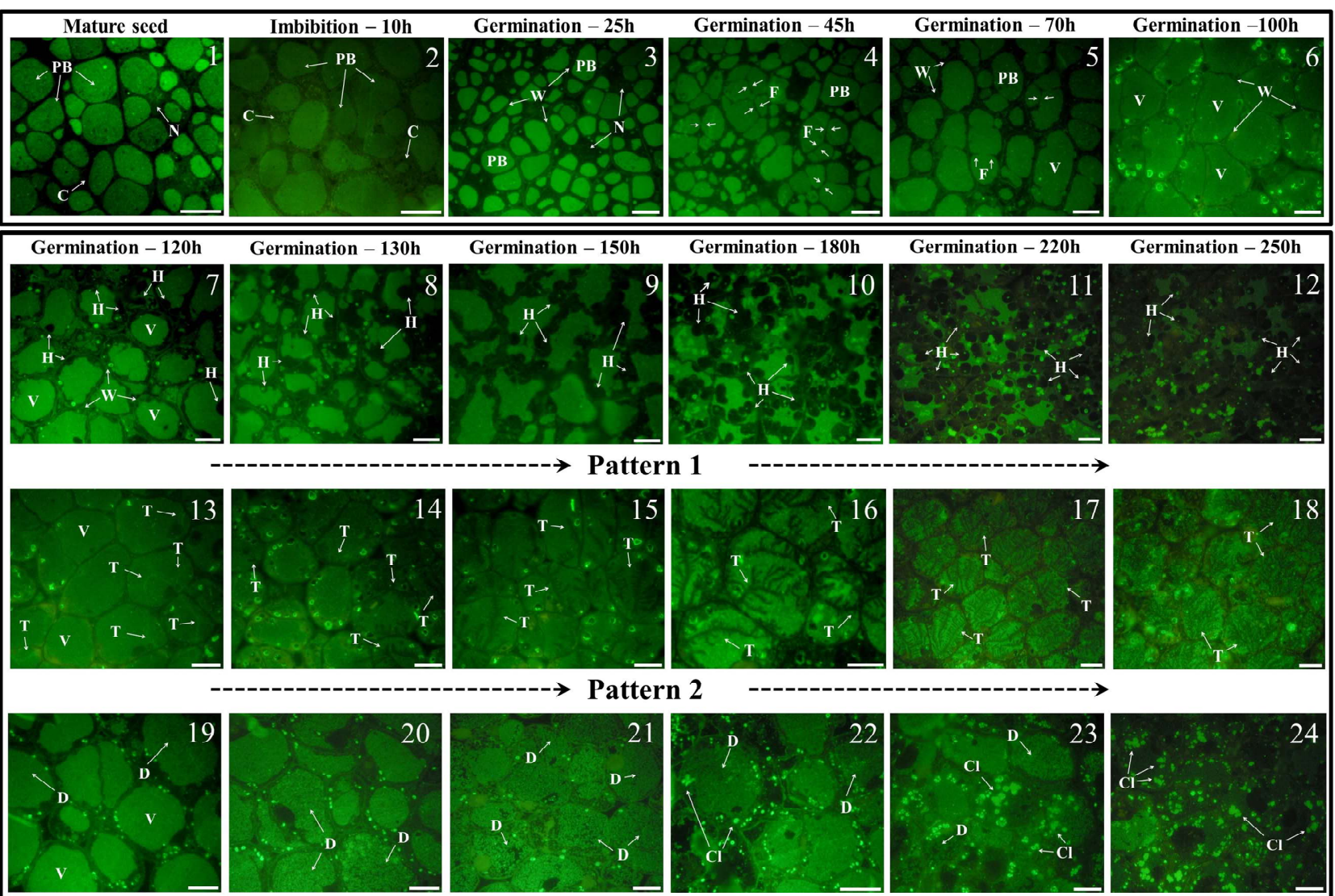

Pattern 3
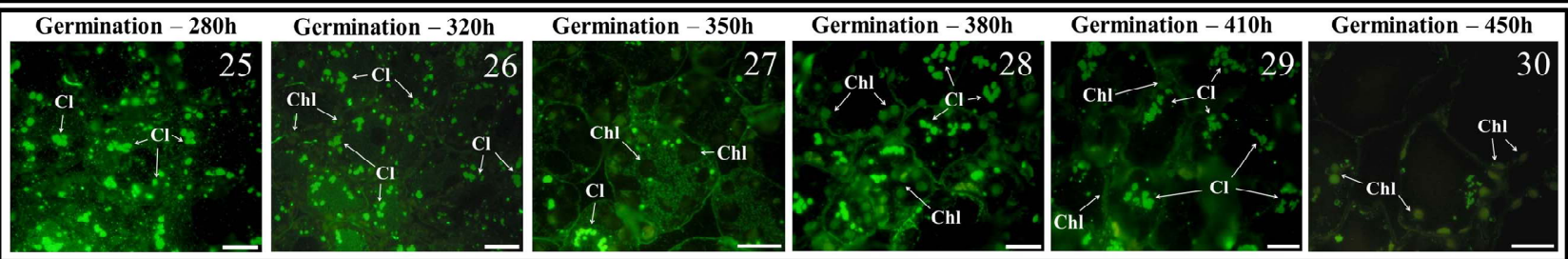

Figure 3. Immunofluorescence localization of 11S-type globulins in olive cotyledon cells during seedling germinating states. Images 1 to 6 show the cytological changes taking place in cotyledon cells during seed imbibition, and until $100 \mathrm{~h}$ of in vitro germination. The main feature during this period of germination is the fusion of protein bodies resulting in a big vacuole containing the SSPs. Images 7 to 24 show three pathways of SSPs mobilization from PBs during in vitro germination (120 to $250 \mathrm{~h}$ ). These pathways are named as "Holes" (images 7 to 12), "Trees-like structures" (images 13 to 18), and "Whole Disintegration" (images 19 to 24). Images 25 to 30 show the final stages of proteins mobilization and degradation from PBs (280 to $450 \mathrm{~h}$ ), where irregular proteins cluster are the rests of SSPs in the final stages of degradation, and chloroplast and cell walls auto-fluorescence is increasing. $\mathrm{C}=$ cell; $\mathrm{CHL}=$ chloroplast; $\mathrm{CL}=$ cluster; $\mathrm{D}=$ whole disintegration; $\mathrm{F}=$ fusion; $\mathrm{H}=\mathrm{Hole} ; \mathrm{N}$ $=$ nucleus; $\mathrm{PB}=$ protein body; $\mathrm{T}=$ trees-like structures; $\mathrm{V}=$ vesicle; $\mathrm{W}=$ cell wall; scale barr $=20 \mu \mathrm{m}$.

\section{Discussion}

Previous studies have demonstrated that not significant degradation and turnover of SSPs occurs at mature stage in legume seeds [18], which indicates that suitable strategies are protecting storage proteins against a premature proteolytic attack [4]. In addition, at the end of seed maturation, de novo synthesis of proteins is almost completed, in agreement with different species such as Medicago truncatula, Pisum sativum and Arabidopsis thaliana

\section{[19-21].}

Furthermore, at mature stage of M. truncatula various populations of vicilins PBs have been identified, concomitantly with a peak of vicilins genes expression [22]. In the present study, morphometric analysis showed different populations of PBs in olive cotyledon, containing mainly legumin-like proteins when immunohistochemical analysis was performed (Figure 2, Table 1). Interestingly, this is an important feature that may differenti- 

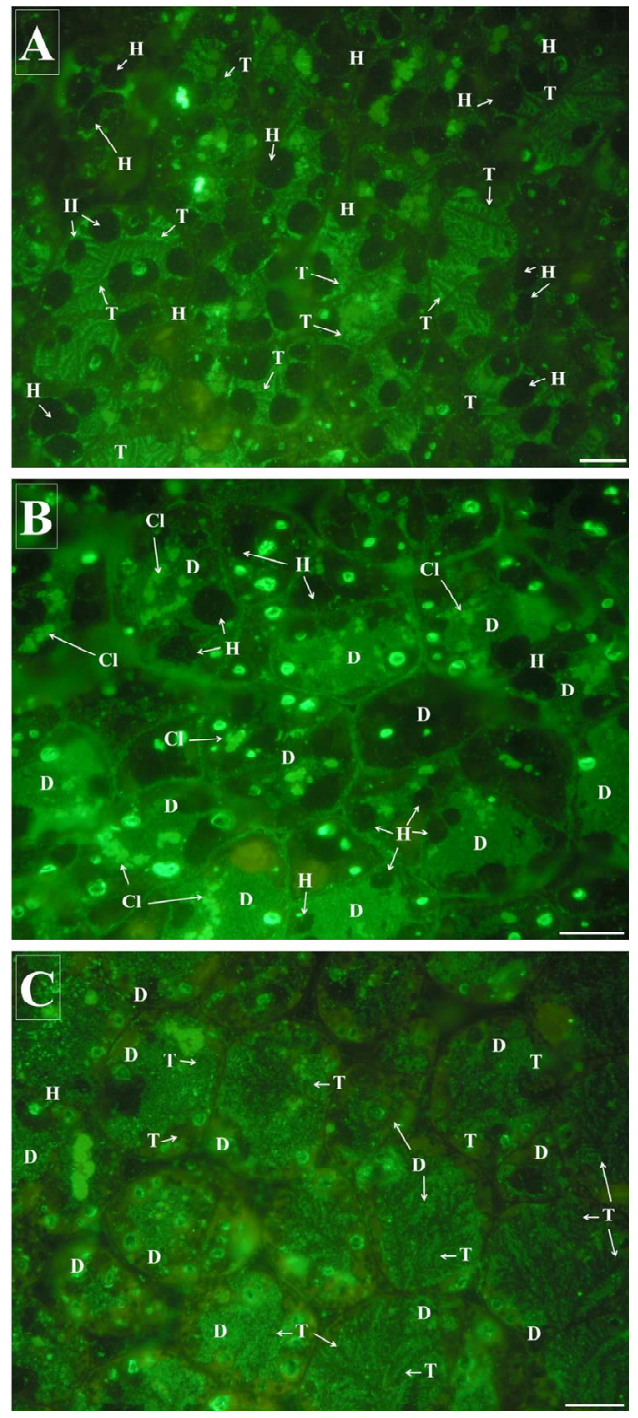

Figure 4. Mobilization patterns concomitance in cotyledon cells of germinating seedling. (A) Patterns 1 and 2; (B) patterns 1 and 3; and (C) patterns 2 and 3 were found in individual cells during SSPs mobilization and degradation. $C L$ = cluster; $\mathrm{D}=$ whole disintegration; $\mathrm{H}=$ Hole; $\mathrm{T}=$ trees-like structures; scale barr $=20 \mu \mathrm{m}$.

ate olive cotyledon cells from those of the endosperm (Figure 2) since homogeneous population of PBs were found in endosperm cells after performing stainability and immunofluorescence analyses. Additionally, other features such as the regular size and equally distributed PBs number per cell (Figure 2, Table 1) contribute to differentiate cotyledon and endosperm cells when compared with the heterogeneity of PBs populations present in cotyledon tissue. These differences between endosperm and cotyledon PBs may be due to selective accumulation/packaging of mature polypeptides as well as composition in SSPs inside the different PBs of mature polypeptides [23]. Variability of PBs populations at ma- ture stages may also be strongly influenced by the type of cell in these seed tissues, SSPs synthesis and transport inside vacuoles via ER-Golgi and/or direct ER-vacuole pathways, which ultimately depend on the cellular conditions [24,2]. Overall, these differences may also have a strong influence in the mobilization of legumin-like and other SSPs, according to the differential patterns showed in the current study.

Protein turnover is essential for seed germination and plant development [18]. Upon seed germination, s substantial proteolysis of SSPs provides the necessary amino acids to accomplish different physiological processes during plant development $[7,9,10]$.

In this study, we have shown that legumin-like proteins degradation in PBs may start either within the protein mass in the large central vacuole (pattern 3 or "Whole Disintegration") with a diffuse fragmentation of the proteinaceous masses, or could initiate along the periphery (pattern 1 or "Holes", and pattern 2 or "Treeslike Structures") (Figures 3, 4). The internal character of SSPs mobilization and degradation suggests that the proteolytic enzymes were originated within the proteinaceous mass and accumulated inactively together with SSPs waiting for further activation [25]. Otherwise, peripheral degradation suggests that the proteolytic enzymes were associated with the delimiting PBs membrane or originated outside the protein body. This can be attributed to some protein bodies not receiving lytic enzymes when they are fashioned or somehow the proteolytic content is not activated when SSPs of these PBs have to be mobilized.

Diverse proteinases are intricately involved in developmental changes in plant cells, i.e. endo- and exopeptidases are present in the PBs of dry seeds of many plants $[26,27]$, which underestimate the importance of the regulation of proteolytic processes. Furthermore, plant cells contain different types of vacuoles that perform a multitude of functions $[5,6,28]$. The composition and architecture of a given vacuole system can change dramatically during seedling germinating stages and plant cell development $[28,29]$. Multiple and sequential processes for proteins mobilization and transport into vacuoles as well as processing and degradation by proteinases make possible proteins turn-over and plant differentiation [30]. According to our data, it is plausible that different patterns of legumin-like protein mobilization are occurring in the same cell of the cotyledon, becoming evident in specific periods of germination (Figure 4). Two degradation patterns can be observed between 100 and $250 \mathrm{~h}$ of germination, while a progressive degradation of legumin-like proteins into very small masses or clusters was determined between 100 to $130 \mathrm{~h}$ of seed germination. These patterns of SSPs mobilization and 
further proteins degradation seem to be characterized by a contemporaneous multi-focal activation of proteolytic enzymes. These combinations of different degradation patterns of SSPs may result either from different protein contents and/or from different storage characteristics of the proteins, enhancing the efficiency of proteins mobilization in periods of high amino acids demand such as seed germination process. In addition, different proteolytic enzymes originated outside of PBs may be involved in these patterns since concomitance of external patterns of mobilization (Figure 4(A)), or even combination of inactively accumulated enzymes and externally fused with the same PB are promoting mobilization and degradation of SSPs from the same PB (Figures 4(B) and (C)).

The germination process is frequently characterized by a tissue-dependent asynchrony, with the germination beginning in radical tips, pre-vascular strands, and in sub-epidermal cell layers where growth and differentiation are also being initiated [31]. Moreover, mobilization of stored compounds in germinating seeds does not occur in all cells and tissues simultaneously but follows specific spatial and temporal patterns [12,32], and also vary depending of the seed specie and differentially dependent in endosperm and cotyledon of the light/dark exposition, and/or type of radiation [33]. Vicia sativa showed that the first storage proteins to be mobilized were located in embryo axis cells, and that mobilization of the globulins stored in the cotyledons typically starts thereafter $[12,34$, $35]$. In the present study, we have showed that leguminlike proteins mobilization is a more active process after they have been re-located in a large vacuole as a result of PBs fusion in cotyledon cells during the early-stages of germination in comparison with the imbibition stage (Figure 3, picture 6). One of the most important physiological changes in the seed at this stage is the activation of a bulk of proteinases enzymes, necessary for SSPs mobilization [36]. However, the possibility of the de novo synthesis cannot be ruled out because it would also contribute to a certain initial degree of mobilization of storage proteins (7S vicilins and $11 \mathrm{~S}$ legumins) during seed imbibition [25,34,37] as observed in the present study (Figure 3, picture 2), or after periods of high demand of amino acids as suggested by the combination of mobilization patterns for more efficient and fast SSPs degradation (Figure 4). Furthermore, a proteinase pattern of genes expression finely controlled may be also reflected in the pattern of mobilization (and break-down) during olive seed germination, due to differential content and functionality carrying out by legumin-like as well as vicilin-like proteins in different PBs [12], markedly highlighted by the significant immunofluorescence intensity differences $(p<0.001)$ estimated amongst PBs in coty- ledon and endosperm (Mann-Whitney U test).

After 5 days of olive seed in vitro germination (Figure 3, from picture 6), the fluorescence from the 11S globulins immunolocalization was located in the whole cytoplasm, likely related to the presence of a large central vacuole. This transformation is a mechanically-dependent process that involves vacuoles fusion and membrane restructuring, in addition to acidification of the vacuole lumen, and mobilization of the stored molecules [5,38]. The acidic environment of the vacuolar environment may be another additional control mechanism of the SSPs mobilization. Low $\mathrm{pH}$ facilitates conformational changes of proteins and enhances their accessibility to proteinases action [39]. Moreover, acidic cysteine proteinases (CPRs) families' papin- and legumain-like cysteine endopeptidases are responsible for the degradation of globulins accumulated in the dry seeds and for the initiation of globulin mobilization after imbibition [40,41]. CPRs gradually increase their activity during the seed germination $[11,40]$, and play an essential role in the hydrolysis and mobilization of proteins during seed germination in cereals [42] and dicotyledonous plants [27]. The activity of these proteases during SSPs mobilization is spatio-temporally highly regulated $[43,44]$, as previously demonstrated in vetch cotyledon $[12,35,41]$. This activity may therefore occur in olive cotyledon cells, since no further degradation is noticed after seed imbibition, while a period of extensive fusion of PBs is taking place in olive cotyledon cells (Figure 3, pictures 3 to 5).

After 5 days of germination, we have identified three different SSPs mobilization patterns in PBs of embryo cells (Figure 3, pictures 7 to 24). This is a major feature that can differentiate olive seed germination from other species. To the best of our knowledge, the present study describes for the first time these three patterns of SSPs mobilization in PBs of cotyledon cells. These seed proteins mobilization patterns may occur concomitantly in the same type of cell, but individual patterns of proteins mobilization in different type of cells of cotyledon may not be ruled out. This later possibility is in agreement with the fact that differential enzymatic content of lytic vacuoles may be developmentally synthesized in a tissue-specific manner, which may play an important role in determining the pattern of SSPs mobilization [6]. Indeed, 42 proteinases were found to be involved in the germination of barley seeds, and 27 among them belonged to the CPRs family $[45,46]$. In addition to previous observations, the translocation of proteinases into specific target vacuoles for subsequent activation and proteins degradation is necessary for SSP mobilization [47].

\section{Conclusions}

This study substantially helps understanding the com- 
plexity of antagonistic physiological processes such as correct seed proteins' accumulation and their further mobilization by orchestrating different physiological processes and supporting seedling growth and plant development. Several differential features have arisen in PBs populations of endosperm and cotyledon, emphasizing the specific nature and functionality of each seed tissue. These features are developmentally strengthened to drive plant growth and development, i.e. endosperm as nurturing tissue for the embryo to give rise to an entire new plant.

The identification and description of three differential cytological patterns of mobilization of seed storage proteins from PBs of cotyledon cells by using legumin-like proteins as a molecular marker may provide a better understanding of SSPs differential functionality during seed germination. These different mobilization patterns, i.e. diffuse fragmentation of the proteins masses ("Whole Disintegration" pattern) and peripheral progressive PBs erosion ("Holes" and "Trees-like Structures" patterns), reflect the implications of different physiological factors like mature SSPs properties (polypeptide composition, storage and packaging), cotyledon cell types, and the vacuolar enzymatic composition and differential proteolytic enzymes activation, in determining the type(s) of mobilization(s) pattern(s) and further SSPs degradation during the seed germination time-course and plant growth. Future studies will remain necessary to better understand the nature and functionality of the new cytological patterns of SSPs mobilization described in this study.

\section{Acknowledgements and Funding}

This study was supported by the following grants: BFU2011-22779, CICE (Junta de Andalucía) P2010AGR6274 and P2011-CVI-7487.

JCJ-L thanks Spanish CSIC and the European Marie Curie research program (FP7-PEOPLE-2011-IOF) for his I3P-BPD-CSIC and PIOF-GA-2011-301550 grants, respectively. MCH-S thanks The University of Queensland for a postdoctoral research fellowship.

Authors would like to thank C. Martinez-Sierra for excellent technical assistance.

The funders had no role in study design, data collection and analysis, decision to publish, or preparation of the manuscript.

\section{Authors' Contributions}

JCJ-L conceived and designed the study. JCJ-L performed the study. JCJ-L and MCH-S analyzed, discussed and assessed the resulting data. JCJ-L contributed reagents/materials/analysis tools. JCJ-L and MCH-S wrote the paper.

\section{REFERENCES}

[1] M. Otegui, R. Herder, J. Schulze, R. Jung and A. Staehelin, "The Proteolytic Processing of Seed Storage Proteins in Arabidopsis Embryo Cells Starts in the Multivesicular Bodies," Plant Cell, Vol. 18, No. 10, 2006, pp. 2567-2581. http://dx.doi.org/10.1105/tpc.106.040931

[2] E. M. Herman and B. A. Larkins, "Protein Storage Bodies and Vacuoles," Plant Cell, Vol. 11, No. 4, 1999, pp. 601614.

[3] M. Otegui, R. Herder, J. Schulze, R. Jung and A. Staehelin, "The Proteolytic Processing of Seed Storage Proteins in Arabidopsis Embryo Cells Starts in the Multivesicular Bodies," Plant Cell, 18, No. 10, 2006, 2567-2581. http://dx.doi.org/10.1105/tpc.106.040931

[4] A. D. Shutov, H. Bäulein, F. R. Blattner and R. Müntz, "Storage and Mobilization as Antagonistic Functional Constraints on Seed Storage Globulin Evolution," Journal of Experimental Botany, Vol. 54, No. 388, 2003, pp. 1645-1654. http://dx.doi.org/10.1093/jxb/erg165

[5] L. Jiang, T. E. Phillips, C. A. Hamm, Y. M. Drozdowicz, P. A. Rea, M. Maeshima, S. W. Rogers and J. C. Rogers, "The Protein Storage Vacuole: A Unique Compound Organelle," Journal Of Cell Biology, Vol. 155, No. 6, 2001, pp. 991-1002. http://dx.doi.org/10.1083/jcb.200107012

[6] H. Q. Zheng and A. Staehelin, "Protein Storage Vacuoles Are Transformed into Lytic Vacuoles in Root Meristematic Cells of Germinating Seedlings by Multiple, Cell Type-Specific Mechanisms," Plant Physiology, Vol. 155, No. 4, 2011, pp. 629-639. http://dx.doi.org/10.1104/pp.110.170159

[7] H. T. Kim, U.-K. Choi, S. H. Ryu, S. J. Lee and O.-S. Kwon, "Mobilization of Storage Proteins in Soybean Seed (Glycine max L.) during Germination and Seedling Growth," Biochimica and Biophysica Acta, Vol. 1814, No. 9, 2011, pp. 1178-1187.

http://dx.doi.org/10.1016/j.bbapap.2011.05.004

[8] I. M. Brocard-Gifford, T. J. Lynch and R. R. Finkelstein, "Regulatory Networks in Seeds: Integrating Developmental, Abscisic Acid, Sugar, and Light Signaling," Plant Physiology, Vol. 131, No. 1, 2003, pp. 78-92. http://dx.doi.org/10.1104/pp.011916

[9] A. L. Tan-Wilson and K. A. Wilson, "Mobilization of Seed Protein Reserves," Physiologia Plantarum, Vol. 145, No. 1, 2012, Vol. 140-153.

[10] J. D. Bewley, K. Bradford, H. Hilhorst and H. Nonogaki, "Seeds: Physiology of Development, Germination and Dormancy," 3rd Edition, Springer, Berlin, 2013, p. 195.

[11] H. Nonogaki, F. Chen and K. Bradford, "Mechanisms and Genes Involved in Germination Sensu Stricto," In: K. Bradford and H. Nonogaki, Eds., Seed Development, Dormancy and Germination, Blackwell, Oxford, 2007, pp. 264-304. http://dx.doi.org/10.1002/9780470988848.ch11

[12] J. Tiedemann, B. Neubohn and K. Muntz, "Different Functions of Vicilin and Legumin Are Reflected in the 
Histopattern of Globulin Mobilization during Germination of Vetch (Vicia sativa L.)," Planta, Vol. 211, No. 1, 2000, pp. 1-12. http://dx.doi.org/10.1007/s004250000259

[13] A. Schlereth, C. Becker, C. Horstmann, J. Tiedemann and K. Muntz, "Comparison of Globulin Mobilization and Cysteine Proteinases in Embryonic Axes and Cotyledons during Germination and Seedling Growth of Vetch (Vicia sativa L.)," Journal of Experimental Botany, Vol. 51, 349, 2000, pp. 1423-1433. http://dx.doi.org/10.1093/jexbot/51.349.1423

[14] T. Murashige and F. Skoog, "A Revised Medium for Rapid Growth and Bioassays with Tobacco Tissue Cultures," Plant Physiology, Vol. 15, No. 3, 1962, pp. 473497. http://dx.doi.org/10.1111/j.1399-3054.1962.tb08052.x

[15] J. A. Bergeron and M. Singer, "Metachromasy: An Experimental and Theoretical Reevaluation," Journal of Biophysical and Biochemical Cytology, Vol. 4, No. 4, 1958, pp. 433-457. http://dx.doi.org/10.1083/jcb.4.4.433

[16] J. Parker, "Stains for Strands in Sieve Tubes," Stain Technology, Vol. 40, No. 4, 1965, pp. 223-225.

[17] J. D. Alché, J. C. Jimenez-Lopez, W. Wang, A. J. Castro and M. I. Rodriguez-Garcia, "Biochemical Characterization and Cellular Localization of 11S Type Storage Proteins in Olive (Olea europaea L.) Seeds," Journal of Agricultural and Food Chemistry, Vol. 54, No. 15, 2006, pp. 5562-5570. http://dx.doi.org/10.1021/jf060203s

[18] J. T. Madison, J. F. Thompson and A. E. Muenster, "Turnover of Storage Protein in Seeds of Soybean and Pea," Annals of Botany, Vol. 47, No. 1, 1981, pp. 65-73.

[19] K. Gallardo, C. Signor, J. Vandekerckhoye, R. Thompson and J. Burstin, "Proteomics of Medigo tranculata Seed Development Establishes the Time Frame of Diverse Metabolic Processes Related to Reserve Accumulation," Plant Physiology, Vol. 133, No. 2, 2003, pp. 664-668. http://dx.doi.org/10.1104/pp.103.025254

[20] B. Hoh, G. Hinz, B. K. Jeong and D. G. Robinson, "Protein Storage Vacuoles Form de Novo during Pea Cotyledon Development," Journal of Cell Science, Vol. 108, Pt. 1, 1995, pp. 299-310.

[21] C. Job, L. Rajjou, Y. Lovigny, M. Belghazi and D. Job, "Patterns of Protein Oxidation in Arabidopsis Seeds and during Germination," Plant Physiology, Vol. 138, No. 2, 2005, pp. 790-802. http://dx.doi.org/10.1104/pp.105.062778

[22] M. Abirached-Darmency, F. Dessaint, E. Benlicha and C. Schneider, "Biogenesis of Protein Bodies during Vicilin Accumulation in Medicago truncatula Immature Seeds," BMC Research Notes, Vol. 5, 2012, p. 409. http://dx.doi.org/10.1186/1756-0500-5-409

[23] L. Tian, L. L. Dai, Z. J. Yin, M. Fukuda, T. Kumamaru, X. B. Dong, X. P. Xu and L. Q. Qu, "Small GTPase Sar1 Is Crucial for Proglutelin and $\alpha$-Globulin Export from the Endoplasmic Reticulum in Rice Endosperm," Journal of Experimental Botany, Vol. 64, No. 10, 2013, pp. 28312845. http://dx.doi.org/10.1093/jxb/ert128

[24] K. Muntz, "Deposition of Storage Proteins," Plant Molecular Biology, Vol. 38, No. 1-2, 1998, pp. 77-99.

\section{http://dx.doi.org/10.1023/A:1006020208380}

[25] A. Zienkiewicz, J. C. Jimenez-Lopez, K. Zienkiewicz, J. D. Alché and M. I. Rodríguez-García, "Development of the Cotyledon Cells during Olive (Olea europaea L.) in Vitro Seed Germination and Seedling Growth," Protoplasma, Vol. 248, No. 4, 2011, pp. 751-765., 2011, pp. 751-765.

[26] G. B. Fincher, "Molecular and Cellular Biology Associated with Endosperm Mobilization in Germinating Cereal Grains," Annual Review of Physiology Plant Molecular Biology, Vol. 40, 1989, pp. 305-346. http://dx.doi.org/10.1146/annurev.pp.40.060189.001513

[27] K. Muntz, "Proteases and Proteolytic Cleavage of Storage Proteins in Developing and Germination Dicot Seeds," Journal of Experimental Biology, Vol. 47, No. 298, 1996, pp. 605-622.

[28] M. Wink, "The Plant Vacuole: A Multifunction Compartment," Journal of Experimental Botany, Vol. 44, 1993, pp. 231-246.

[29] Y. Oda, T. Higaki, S. Hasezawa and N. Kutsuna, "New Insights into Plant Vacuolar Structure and Dynamics," International Review of Cell and Molecular Biology, Vol. 277, 2009, pp. 103-135.

[30] T. Shimada, K. Yamada, M. Kataoka, S. Nakaune, Y. Koumoto, M. Kuroyanagi, S. Tabata, T. Kato, K. Shinozaki, M. Seki, M. Kobayashi, M. Kondo, M. Nishimura and I. Hara-Nishimura, "Vacuolar Processing Enzymes Are Essential for Proper Processing of Seed Storage Proteins in Arabidopsis Thaliana," Journal of Biological Chemistry, Vol. 278, No. 34, 2003, pp. 32292-32299. http://dx.doi.org/10.1074/jbc.M305740200

[31] S. D. V. F. da Rosa, M. B. McDonald, A. D. Veiga, F. del Vilela and I. A. Ferreira, "Staging Coffee Seedling Growth: A Rationale for Shortening the Coffee Seed Germination Test," Seed Science and Technology, Vol. 38, No. 2, 2010, pp. 421-431.

[32] I. Hara and H. Matsubara, "Pumpkin (Cucurbita sp.) seed Globulin. V. Proteolytic Activities Involved in Globulin Degradation in Ungerminated Seeds," Plant and Cell Physiology, Vol. 21, No. 2, 1980, pp. 219-232.

[33] G. Psaras, K. Georghiou and K. Mitrakos, "Red-LightInduced Endosperm Preparation for radicle Protrusion of Lettuce Embryos," Botanical Gazette, Vol. 142, No. 1, 1981, pp. 13-18. http://dx.doi.org/10.1086/337190

[34] A. Schlereth, C. Becker, C. Horstmann, J. Tiedemann and K. Muntz, "Comparison of Globulin Mobilization and Cysteine Proteinases in Embryonic Axes and Cotyledons during Germination and Seedling Growth of Vetch (Vicia sativa L.)," Journal Experimental Botany, Vol. 51, No. 349, 2000, pp. 1423-1433. http://dx.doi.org/10.1093/jexbot/51.349.1423

[35] J. Tiedemann, A. Schlereth and K. Müntz, "Differential Tissue-Specific Expression of Cysteine Proteinases Forms the Basis for the Fine-Tuned Mobilization of Storage Globulin during and after Germination in Legume Seeds," Planta, Vol. 212, No. 5-6, 2001, pp. 728-738. http://dx.doi.org/10.1007/s004250000435

[36] K. Müntz, "Protein Dynamics and Proteolysis in Plant 
Vacuoles," Journal of Experimental Botany, Vol. 58, No. 10, 2007, pp. 2391-2407.

[37] E. L. Virgil and T. K. Fang, "Protease Activities and Elongation Growth of Excised Cotton Seed Axes during the First 24h of Imbibition," Seed Science Research, Vol. 5, No. 4, 1995, pp. 201-207.

[38] P. C. Bethke, S. J. Swanson, S. Hillmer and R. L. Jones, "From Storage Compartment to Lytic Organelle: The Metamorphosis of the Aleurone Protein Storage Vacuole," Annals of Botany, Vol. 82, No. 4, 1998, pp. 399-412. http://dx.doi.org/10.1006/anbo.1998.0702

[39] D. Gruis, J. Schulze and R. Jung, "Storage Protein Accumulation in the Absence of the Vacuolar Processing Enzyme Family of Cysteine Proteases," Plant Cell, Vol. 16, No. 1, 2004, pp. 270-290. http://dx.doi.org/10.1105/tpc.016378

[40] C. Shi and L. L. Xu, "Characters of Cysteine Endopeptidases in Wheat Endosperm during Seed Germination and Subsequent Seedling Growth," Journal of Integrative Plant Biology, Vol. 51, No. 1, 2009, pp. 52-57. http://dx.doi.org/10.1111/j.1744-7909.2008.00778.x

[41] J. Fischer, C. Becker, S. Hillmer, C. Horstmann, B. Neubohn, A. Schlereth, V. Senyuk, A. Shutov and K. Müntz, "The Families of Papain- and Legumain-Like Cysteine Proteinases from Embryonic Axes and Cotyledons of Vicia Seeds. Developmental Patterns, Intracellular Localization and Functions in Globulin Proteolysis," Plant Molecular Biology, Vol. 43, No. 1, 2000, pp. 83-101. http://dx.doi.org/10.1023/A:1006456615373
[42] N. Y. Zhang and B. L. Jones, "Purification and Partial Characterization of a 31-kDa Cysteine Endopeptidase from Germinated Barley," Planta, Vol. 199, No. 4, 1996, pp. 565-572. http://dx.doi.org/10.1007/BF00195188

[43] G. Galili and E. M. Herman, "Protein Bodies: Storage Vacuoles in Seeds," Advances in Botanical Research, Vol. 25, 1997, pp. 113-140.

[44] Y. J. Ahn and G. Q. Chen, "Temporal and Spatial Expression of 2S Albumin in Castor (Ricinus communis L.)," Journal of Agricultural and Food Chemistry, Vol. 55, No. 24, 2007, pp. 10043-10049. http://dx.doi.org/10.1021/jf071272p

[45] N. Y. Zhang and B. L. Jones, "Characterization of Germinated Barley Endoproteolytic Enzymes by Two Dimensional Gel Electrophoresis," Journal of Cereal Science, Vol. 21, No. 2, 1995, pp. 145-153. http://dx.doi.org/10.1016/0733-5210(95)90030-6

[46] N. Y. Zhang and B. L. Jones, "Polymorphism of Aspartic Proteinases in Resting and Germinating Barley Seeds," Cereal Chemistry, Vol. 76, No. 1, 1999, pp. 134-138. http://dx.doi.org/10.1094/CCHEM.1999.76.1.134

[47] M. J. Chrispeels and E. M. Herman, "Endoplasmic Reticulum-Derived Compartments Function in Storage and as Mediators of Vacuolar Remodeling via a New Type of Organelle, Precursor Protease Vesicles," Plant Physiology, Vol. 123, No. 4, 2000, pp. 1227-1233. http://dx.doi.org/10.1104/pp.123.4.1227 